\title{
The effect of wear phenomena of grinding wheels with sol-gel alumina on chip formation during internal cylindrical plunge grinding of 100Cr6 steel
}

\author{
Krzysztof Nadolny $^{1}$ - Wojciech Kapłonek ${ }^{2}$
}

Received: 28 October 2015 / Accepted: 9 February 2016 / Published online: 23 February 2016

(C) The Author(s) 2016. This article is published with open access at Springerlink.com

\begin{abstract}
The article presents the results of experimental investigations to determine the effect of wear phenomena of grinding wheels with sol-gel alumina abrasive grains on chip formation during internal cylindrical plunge grinding of $100 \mathrm{Cr} 6$ steel. Basic wear phenomena conducted during the grinding process using microcrystalline sintered corundum abrasives are described. In order to expand our knowledge of this phenomena, experimental tests were conducted in two stages. In stage 1, only one opening was machined, which corresponded to the removal of $464 \mathrm{~mm}^{3}$ of workpiece material. In the second stage, the process was carried to machine 100 subsequent openings (material removal $V_{w}=46$, $400 \mathrm{~mm}^{3}$ ). Such methodology allowed one to observe changes in the form of chips resulting from the progressive wear of the grinding wheel components. The form and size of the chips were identified by recording and analyzing the SEM micrographs of the chips for both grinding stages, respectively. Conducted studies have shown that the dominant type of chips, shaped in the initial period of the grinding wheel's life, are large (several hundred $\mu \mathrm{m}$ in length) flowing-type chips resulting from material removal by sharp cutting edges of
\end{abstract}

Krzysztof Nadolny

krzysztof.nadolny@tu.koszalin.pl

Wojciech Kapłonek

wojciech.kaplonek@tu.koszalin.pl

1 Department of Production Engineering, Faculty of Mechanical Engineering, Koszalin University of Technology, Raclawicka 15-17, 75-620 Koszalin, Poland

2 Subject Group of Metrology and Quality, Department of Production Engineering, Faculty of Mechanical Engineering, Koszalin

University of Technology, Racławicka 15-17,

75-620 Koszalin, Poland abrasive grain active vertices. At the end of the grinding wheel's life, when active vertices of abrasive grains have clear signs of large fatigue and thermo-fatigue wear, only in the near-edge zones of the wheel can flowing-type and shearingtype chips (usually less than $100 \mu \mathrm{m}$ in length) be observed, while knife-type and slice-type microchips were predominately registered on the whole grinding wheel surface.

Keywords Plunge grinding · Chips · Wear · Grinding wheel · SEM $\cdot$ Steel 100Cr6

$\begin{array}{ll}\text { Nomenclature } \\ \text { AE } & \text { Acoustic emission } \\ \text { AOI } & \text { Area of interest } \\ \text { BEI } & \text { Backscattered electron detector } \\ \text { cBN } & \text { Cubic boron nitride } \\ \text { DIP } & \text { Digital image processing } \\ \text { GF } & \text { Grinding fluid } \\ \text { GWAS } & \text { Grinding wheel active surface } \\ \text { HSG } & \text { High-speed grinding } \\ \text { HVM } & \text { High vacuum mode } \\ \text { LVM } & \text { Low vacuum mode } \\ \text { MMC } & \text { Metal-matrix composite } \\ \text { MQL } & \text { Minimum quantity lubrication } \\ \text { SEI } & \text { Secondary electron image } \\ \text { SEM } & \text { Scanning electron microscope } \\ \text { UHSG } & \text { Ultra-high-speed grinding } \\ a_{a} & \text { Axial engagement (mm) } \\ a_{d} & \text { Dressing allowance (mm) } \\ a_{e} & \text { Working engagement }(\text { machining allowance })(m m) \\ a_{e} \text { tot } & \text { Total working engagement }(\text { machining allowance) } \\ & \text { (mm) } \\ A_{n} & \text { Area of measured object }\left(\mu \mathrm{m}^{2}\right) \\ b_{a v r} & \text { Average width of chip }(\mu \mathrm{m}) \\ b_{m a x} & \text { Maximum width of chip }(\mu \mathrm{m})\end{array}$


$b_{\text {min }} \quad$ Minimum width of chip ( $\left.\mu \mathrm{m}\right)$

$b_{w} \quad$ Workpiece width (mm)

$d_{s} \quad$ Grinding wheel outer diameter ( $\left.\mathrm{mm}\right)$

$d_{w} \quad$ Workpiece diameter (mm)

$G \quad$ G-ratio $\left(\mathrm{mm}^{3} / \mathrm{mm}^{3}\right)$

$H \quad$ Grinding wheel inner diameter ( $\mathrm{mm})$

$i_{d} \quad$ Number of dressing passes

$l \quad$ Stylus profilometer tracing length ( $\mathrm{mm})$

$l_{\max } \quad$ Maximum traverse of stylus profilometer column (mm)

$n_{s} \quad$ Grinding wheel rotational speed $\left(\mathrm{min}^{-1}\right)$

$n_{s d} \quad$ Grinding wheel rotational speed while dressing $\left(\min ^{-1}\right)$

$n_{w} \quad$ Workpiece rotational speed $\left(\mathrm{min}^{-1}\right)$

$P \quad$ Grinding power (W)

$P_{c h} \quad$ Chip perimeter $(\mu \mathrm{m})$

$Q_{d} \quad$ Diamond dresser mass (kt)

$Q_{G F} \quad$ Grinding fluid flow rate $\left(\mathrm{L} \mathrm{min}^{-1}\right)$

$r \quad$ Stylus profilometer tip radius $(\mu \mathrm{m})$

$\mathrm{Ra} \quad$ Arithmetic mean deviation of the workpiece roughness profile $(\mu \mathrm{m})$

$R d q \quad$ Root-mean-square slope of the profile within a sampling length $\left(^{\circ}\right)$

rms Root-mean-square roundness deviation from mean circle $(\mu \mathrm{m})$

$R S m \quad$ Mean width of roughness profile elements within a sampling length $(\mu \mathrm{m})$

$R z \quad$ Maximum height of the profile within a sampling length $(\mu \mathrm{m})$

$S \quad$ Standard deviation

$T \quad$ Grinding wheel total height in the axial direction (mm)

$t_{g} \quad$ Grinding time (s)

Ua SEM microscope accelerating voltage (V)

$v_{f a} \quad$ Axial table feed speed while grinding $\left(\mathrm{mm} \mathrm{s}^{-1}\right)$

$v_{f d} \quad$ Axial table feed speed while dressing $\left(\mathrm{mm} \mathrm{s}^{-1}\right)$

$v_{f r} \quad$ Radial table feed speed while grinding $\left(\mathrm{mm} \mathrm{min}^{-1}\right)$

$v_{s} \quad$ Grinding wheel peripheral speed $\left(\mathrm{m} \mathrm{s}^{-1}\right)$

$v_{w} \quad$ Workpiece peripheral speed $\left(\mathrm{m} \mathrm{s}^{-1}\right)$

$V_{b} \quad$ Volume of bond in the grinding wheel (\%)

$V_{g} \quad$ Volume of abrasive grains in the grinding wheel (\%)

$V_{p} \quad$ Volume of pores in the grinding wheel (\%)

$V_{s} \quad$ Volumetric grinding wheel wear $\left(\mathrm{mm}^{3}\right)$

$V_{w} \quad$ Material removal $\left(\mathrm{mm}^{3}\right)$

$\Delta \quad$ Maximum roundness deviation $(\mu \mathrm{m})$

$\Delta P \quad$ Grinding power gain (W)

\section{Introduction}

For many years, the form of chips generated in machining processes was the source of information on the process conditions, allowing one to define the basic phenomena related to material removal, as well as predicting and evaluating the process quantities. In the literature, many examples can be found regarding the results of investigations in this area concerning various types of machining processes, namely, turning [1-3], milling [4], drilling [5], or grinding. Information from the analysis of the form of such chips is particularly important in investigations of new varieties of the abrasive processes or by determining the effect of process modernization on its course.

Initial work in this area was related with a better understanding and classification of the forms of chips generated in various grinding processes and seeking a relationship between the form of chips and process parameters. Wong and Doyle [6] drew attention to the form of chips throughout the sample issue of the impact of a fragmented zone on an increase in metal removal in the form of thin delaminated wear platelets. The authors demonstrated this effect by observing the forms of chips generated in the examined process, stating that thin delaminated wear platelets are evident when grinding in an inert atmosphere and take the form of oxide hollow spheres (spherical chips, melted globule) when grinding in air. The studies of Malkin [7], as well as Doyle and Dean [8], have pointed out that more perfectly formed spherical chips form as a result of grinding debris undergoing surface oxidation in the atmosphere. This is what causes melting of the grinding debris into a sphere (globule). Spherical chips are formed as a result of ignition of the hot smaller chips in air after their formation, followed by solidification. Letner [9] has indicated that the spark stream, and hence spherical chips formation, does not occur when the grinding process is conducted in a vacuum or in an inert gas. This further demonstrates the importance of oxygen in the formation of the spheres. Tso and $\mathrm{Wu}[10]$ have proposed an equivalent chip-volume parameter to define comparable chip sizes of various grinding conditions. Then, they relate chip-volume to the main grinding quantities such as surface finish, grinding force, and specific energy. The obtained results confirm that this chip-volume parameter is a useful index in accurately predicting and evaluating the grinding quantities of surface grinding process of W1(SK3) steel. An analysis of chips can also give information regarding grinding temperature. In their work, Vedhavalli et al. [11] attempted to correlate carbon depletion in mild steel chips to the heat produced at the grinding zone. Carbon content in chips after grinding were compared against base data generated by heating the workpiece material to various temperatures and studying the carbon content. The obtained results of such a comparison gives one an estimate of the temperature that the chip would have undergone during the grinding process.

Chip analysis is often useful for a better understanding of basic phenomena during grinding of new, hard-to-cut or untypical materials. This problem was also posed by Tso [12] regarding the example of the surface grinding process of Inconel® 718 . He defined in this work six basic types of chips: 
flowing, shearing, ripping, piece, knife, and melting chips. On the basis of experimental studies, Tso described the morphology of chips, the share of individual fractions in a group of chips generated during grinding and the impact of selected parameters of the process on the share of individual types of chips. In this work, the results of analyses obtained for Inconel ${ }^{\circledR}$ alloy 718 referred to the results of the grinding of W1 (SK3) steel. Moreover, Ronald et al. [13] have proposed using chip morphology analysis as an indicator of the response of metal-matrix composite (MMC) to grinding. The authors correlated observations of chip morphology with other parameters of the grinding process, such as grinding temperature, acoustic emission (AE) signal, and vibration. The obtained results proved that chip morphology is a reliable indicator of the response of MMCs to grinding. Peng et al. [14] have investigated the chip generating characteristics in the grinding of brittle materials (polysilicone in this case) with vertical elliptic vibration assistance, which is a highefficiency machining technique for some brittle materials. On the basis of scanning electron microscope (SEM) observations of the generated chips, the authors concluded about the compound effects in ultrasonically assisted process on chip form in ductile mode cutting. Nadolny et al. [15] analyzed the degree of grinding wheel active surface (GWAS) clogging by chips of Titanium Grade $2 \AA$ alloy in the internal cylindrical grinding process. It was shown here that there is the possibility of a significant reduction in the adhesion of chips to the GWAS through the impregnation of the grinding wheel.

Some researchers have used their analysis of chip formation to better understand the high-speed grinding (HSG) and ultra-high-speed grinding (UHSG) processes. Feng et al. [16] carried out tests for 45 steel, $20 \mathrm{Cr}$ alloy. They studied chip morphology, as well as groove morphology, area removal ratio, grinding force ratio, and specific grinding force. The conducted analysis allowed one to conclude that surface integrity can be improved under high-speed conditions. Whereas Zhao et al. [17] studied the chip formation mechanism due to the shock UHSG (up to $720 \mathrm{~m} \mathrm{~s}^{-1}$ ) of Q235A steel. The authors verified the accuracy of the elaborated model of the mechanism of chip formation due to shock in the quasi-fluid phase on UHSG on the basis (among others) and the existence of a quasi-fluid phase in UHSG. Zhao et al. [18] have investigated the chip morphology of the nickel-based superalloy Incolnel ${ }^{\circledR} 718$ during a HSG test with a single diamond and cubic boron nitride (cBN) grain. The authors collected chips from the process conducted under different grinding speeds. The chips were characterized by a crack and segment band feature similar to the cutting segmented chips. The obtained results of these observations show that the grinding speed has an important effect on forces and chip formation, partly due to the temperature variation.
Some of the theoretical analyses associated with the formation of the chip and its parameters (undeformed chip thickness, relative chip volume, chip energy, chip temperature) is verified experimentally by researchers on the basis of the analysis of micromachining traces shaped using single abrasive grain (so-called scratch tests), for example in work of Brinksmeler and Glwerzew [19], or by grinding tests [20-23]. However, in the literature, examples of verification of theoretical calculations on the parameters determining the grinding process by microscopic observations of shaped chips morphology can also be found. Hecker et al. [24] recorded groups of chips produced in the surface grinding process of 52100 (100Cr6) steel using SEM whose images were processed with a digital image processing (DIP) routine to isolate each chip and measure its projected area individually. On the basis of these measurements, a model to infer the undeformed chip thickness from the chip projected area was formulated.

Setti et al. [25] considered chip formation phenomena and chip morphology as important factors in the grinding process conducted using nanofluid as metal-working fluid during the surface grinding of Ti-6Al-4V in minimum quantity lubrication (MQL) mode. Indeed, the authors pointed out that the application of a nanofluid leads to a reduction of tangential forces and grinding zone temperature, while the cooling effect was confirmed by short C-type chips.

All the publications cited above demonstrate a wide range of analysis and the importance of examining the chips generated during the grinding process for the knowledge of elementary phenomena associated with known, modified or new abrasive processes. Therefore, in the present study, the effect of wear phenomena of grinding wheels with sol-gel alumina abrasive grains on chip formation during the internal cylindrical plunge grinding of steel $100 \mathrm{Cr} 6$ was analyzed.

Wear of the grinding wheel components significantly affects the course of the grinding process, including the form of chips obtained therein. In the initial period of operation, the active cutting vertices are sharp, the microcutting process is easily initiated with very little friction, and long flowing-type and shearing-type chips are created. Subsequently, as a result of progressive wear of the GWAS blunting of the abrasive grains occurs, wherein the smoothed vertices (as well as bond bridges) rub against the ground surface more significantly and cause it to have more plastic deformations. All this affects the size of the chips, which become shorter, as well as their form. In the final stage of the grinding wheel's life, clogging of the GWAS often appears. This also significantly influences the type of chips obtained. At this stage, slice-type and knifetype microchips occur, which are parts of the clogging area that fall from the GWAS. The indicated relationship between the state of the GWAS, which is the result of elementary wear phenomena, and the size and form of chips formed during the grinding process directly influences, for example, the thermal load of the workpiece surface and the occurrence of thermal 
defects. This relationship can also affect the efficiency of removing grinding products from the machining zone which, in turn, translates into a shortened wheel life.

\section{Sol-gel alumina abrasives wear phenomena}

Microcrystalline sintered corundum is characterized by a similar hardness and greater ductility than white fused alumina grains, which translates into a greater resistance to brittle fracture. Microcrystalline sintered corundum grains are composed of a large number of minor crystallites, connected through a thin crystalline layer. The grains have a submicrocrystalline structure, with particles sized 0.1-5 $\mu \mathrm{m}$ (however, usually $<1 \mu \mathrm{m}$ ), are more durable, and maintain their shape longer than those made from white fused alumina. In relation to $\mathrm{cBN}$, microcrystalline $\mathrm{Al}_{2} \mathrm{O}_{3}$ does not have such high requirements concerning the stiffness of grinding machines [26, 27].

The dominant microcrystalline active abrasive grain vertexes wear phenomenon is the creation of flat surfaces as a result of their plastic flow [28-30]. It has also been observed that the phenomena of oxide layer shedding and plastically deformed grain layers occur periodically on the smoothedout surfaces of the active vertexes [30, 31]. This process is caused by fatigue and thermo-fatigue wear, as a result of which sharp edges of crystals located below the plastically deformed surface layer are uncovered (Fig. 1).

Such a specific set of wear phenomena of the sol-gel alumina abrasive grains has also a significant impact on chip formation in the grinding zone. For this reason, in this paper, the morphology of chips caught from the grinding zone, as well as chips registered on the grinding wheel active surface after internal cylindrical plunge grinding operation, was analyzed.

\section{Experimental investigations}

The aim of this study was to identify the forms of chips generated in the studied grinding process of $100 \mathrm{Cr} 6$ steel and to determine the effect of progressive wear of the GWAS on their morphology.

\subsection{Methodology of experimental tests}

Experimental tests were conducted in two stages. In stage 1, only one opening was machined, which corresponded to the removal of $464 \mathrm{~mm}^{3}$ of workpiece material. In the second stage, the process was carried out to machine 100 subsequent openings (material removal $V_{w}=46,400 \mathrm{~mm}^{3}$ ). Such methodology allowed one to observe changes in the form of chips resulting from the progressing wear of the GWAS. The form and size of the chips were identified by recording and analyzing the SEM micrographs of chips for both grinding stages, respectively.

The tests were carried out using an experimental position built upon the basis of a universal grinding machine, namely an RUP 28P by Mechanical Works Tarnow SA (Poland), equipped with a spindle, type EV-70/70-2WB produced by Fisher (Switzerland). A detailed description of grinding conditions including the used parameters of dressing and grinding process are shown in Table 1.
Fig. 1 Sol-gel alumina abrasives dominant wear phenomenabased on drawings of the Rappold Winterthur Group and the authors' own material [31]

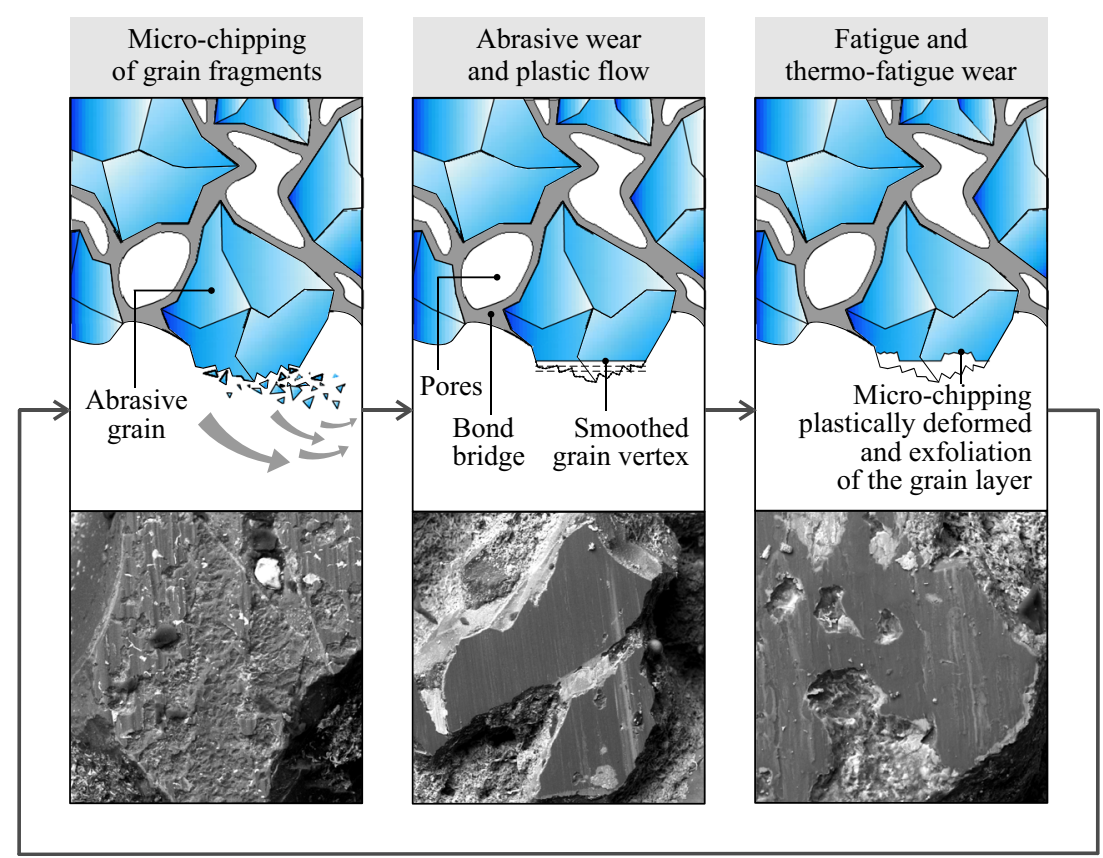


Table 1 Description of grinding conditions

\begin{tabular}{|c|c|}
\hline Grinding process & $\begin{array}{l}\text { Plunge internal cylindrical grinding (with } \\
\text { oscillations) }\end{array}$ \\
\hline Grinding machine & $\begin{array}{l}\text { Universal grinding machine RUP } 28 \mathrm{P} \text { by Mechanical Works Tarnow SA, Poland, } \\
\text { equipped with spindle type EV-70/70-2WB produced by Fisher, Switzerland } \\
\text { (max. rotation } 60,000 \mathrm{~min}^{-1} \text {, power of machine cutting } 5.2 \mathrm{~kW} \text { ) }\end{array}$ \\
\hline Grinding wheel & $1-35 \times 20 \times 10-\mathrm{SG} / \mathrm{F} 46 \mathrm{G} 10 \mathrm{~V}$ \\
\hline $\begin{array}{l}\text { Grinding wheel dressing } \\
\text { parameters }\end{array}$ & $\begin{array}{l}\text { Dresser: single grain diamond dresser with mass: } Q_{d}=1.25 \mathrm{kt} \\
\text { Grinding wheel rotational speed while dressing: } n_{s d}=12,000 \mathrm{~min}^{-1} \\
\text { Dressing allowance: } a_{d}=0.0125 \mathrm{~mm} \\
\text { Axial table feed speed while dressing: } v_{f d}=10 \mathrm{~mm} \mathrm{~s}^{-1} \\
\text { Number of dressing passes: } i_{d}=6\end{array}$ \\
\hline Grinding parameters & $\begin{array}{l}\text { Grinding wheel peripheral speed: } v_{s}=60 \mathrm{~m} \mathrm{~s}^{-1} \\
\text { Axial table feed speed: } v_{f a}=20 \mathrm{~mm} \mathrm{~s}^{-1} \\
\text { Radial table feed speed: } v_{f r}=0.2 \mathrm{~mm} \mathrm{~min}^{-1} \\
\text { Total working engagement (machining allowance): } a_{e} \text { tot }=0.20 \mathrm{~mm} \\
\text { Workpiece peripheral speed: } v_{w}=1.5 \mathrm{~m} \mathrm{~s}^{-1} \\
\text { Grinding time } t_{g}=70 \mathrm{~s} \text { (for single machined opening) } \\
\text { Grinding fluid flow rate: } Q_{G F}=4.0 \mathrm{~L} \mathrm{~min}\end{array}$ \\
\hline Grinding fluid & $5 \%$ water solution of Castrol Syntilo RHS oil given by flood method \\
\hline Workpieces & $\begin{array}{l}\text { Internal cylindrical surface of bearing rings, made of } 100 \mathrm{Cr} 6 \text { steel ( } 62 \pm 2 \mathrm{HRC} \text { ), } \\
\text { internal diameter } d_{w}=40 \mathrm{~mm} \text {, width } b_{w}=18 \mathrm{~mm}\end{array}$ \\
\hline
\end{tabular}

Before starting machining (after dressing) and following grinding, the GWAS morphology was recorded using a SEM microscope. During the tests, changes in the grinding power $P$ were measured for every machined opening and machined surface roughness (described by four parameters on profiles: $R a$, arithmetic mean deviation of the workpiece roughness profile given in $\mu \mathrm{m}$; $R t$, maximum height of the profile within a sampling length given in $\mu \mathrm{m} ; \mathrm{RSm}$, mean width of roughness profile elements within a sampling length given in $\mu \mathrm{m}$; $R d q$, root-mean-square slope of the profile within a sampling length given in degrees) were measured for every five machined openings. Additionally, the circumference profile of the grinding wheel was recorded after dressing and after every fifth ground opening $\left(V_{w}=2320 \mathrm{~mm}^{3}\right)$ with two parameters being set from these measurements: maximum roundness deviation of the grinding wheel $\Delta$ and root-mean-square roundness deviation from mean circle rms.

\subsection{Grinding wheels}

Grinding wheel type 1 was made from microcrystalline sintered corundum SG $^{\mathrm{TM}}$ number 46 and a vitrified bond.
Table 2 presents a description of the grinding wheel used in the experimental tests.

Table 2 Description of grinding wheel used in experiments

\begin{tabular}{ll}
\hline Technical designation & $1-35 \times 20 \times 10-\mathrm{SG} / \mathrm{F} 46 \mathrm{G} 10 \mathrm{~V}$ \\
\hline $\begin{array}{l}\text { Grinding wheel type } \\
\text { Dimensions }\end{array}$ & $\begin{array}{c}1-\text { flat grinding wheel } \\
\text { External diameter } d_{s}=35 \mathrm{~mm}, \\
\text { height } T=10 \mathrm{~mm} \text {, inner } \\
\text { diameter } H=10 \mathrm{~mm}\end{array}$ \\
Abrasive grain type & $\begin{array}{c}\text { Microcrystalline sintered } \\
\text { corundum (sol-gel alumina) }\end{array}$ \\
& $\mathrm{SG}^{\mathrm{TM}}$ by Norton (USA) \\
Abrasive grain fracture no. & 46 \\
Hardness class & $\mathrm{G}$ \\
Structure no. & 10 \\
Bond & Vitrified (amorphous) \\
Volume of grains $\left(V_{g}\right)$ & $42.0 \%$ \\
Volume of bond $\left(V_{b}\right)$ & $11.5 \%$ \\
Volume of pores $\left(V_{p}\right)$ & $46.5 \%$ \\
\hline
\end{tabular}


Fig. 2 General views of measurement systems used in the experimental tests: a stylus profilometer Hommel-Tester T8000 by Hommelwerke; b tabletop contact roundness meter PIK-1A by IICMMS; c scanning electron microscope JSM-5500LV by JEOL
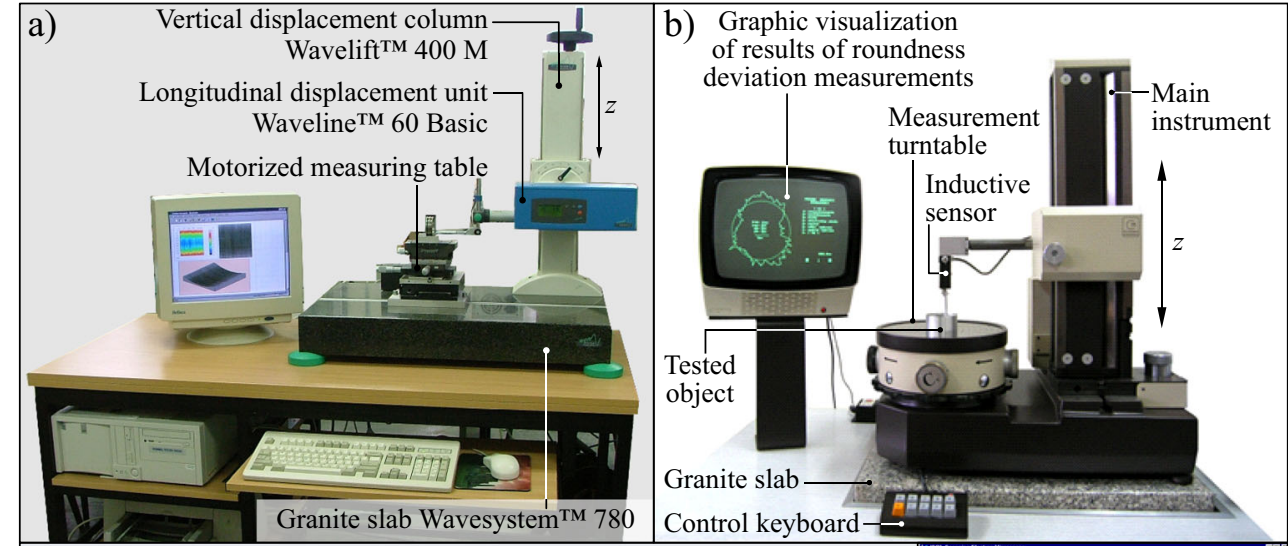

c) ELECTRON $~$ OPTICAL COLUMN UNIT OPERATIONAL UNIT

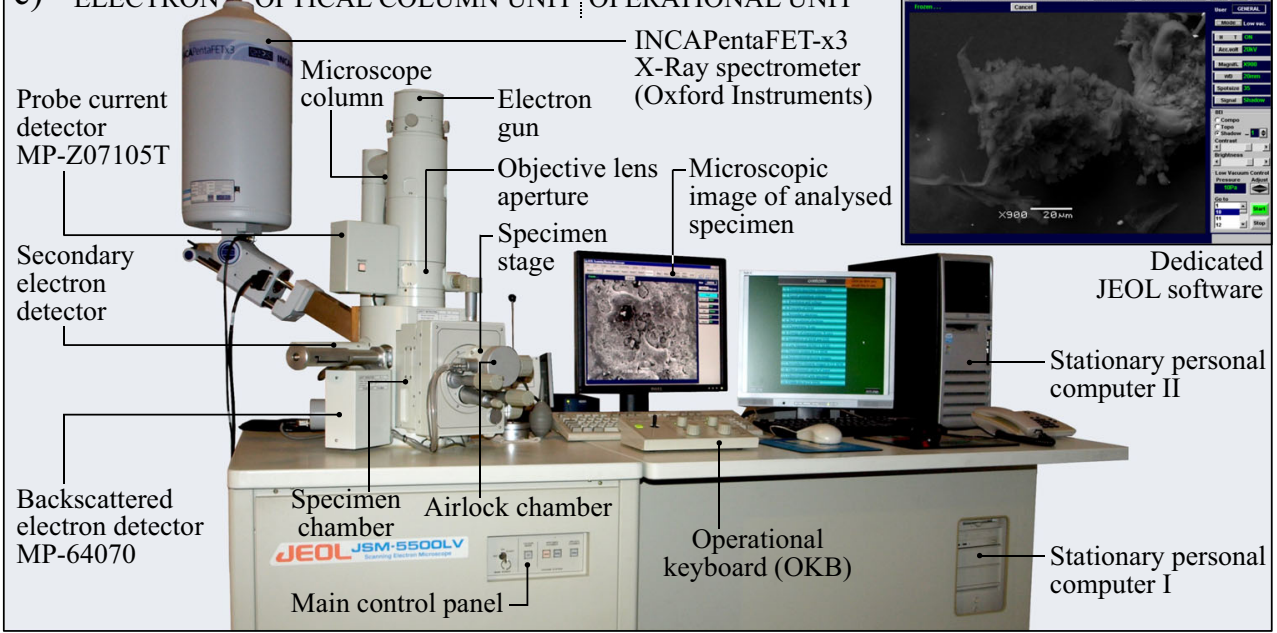

\subsection{Measurement systems}

During the experimental tests, three different measurement systems were generally used. For measurements of the profiles of the workpiece surface, a stylus profilometer Hommel-Tester T 8000 produced by Hommelwerke GmbH (Germany) was used, while analysis of roundness deviation of the grinding wheel was

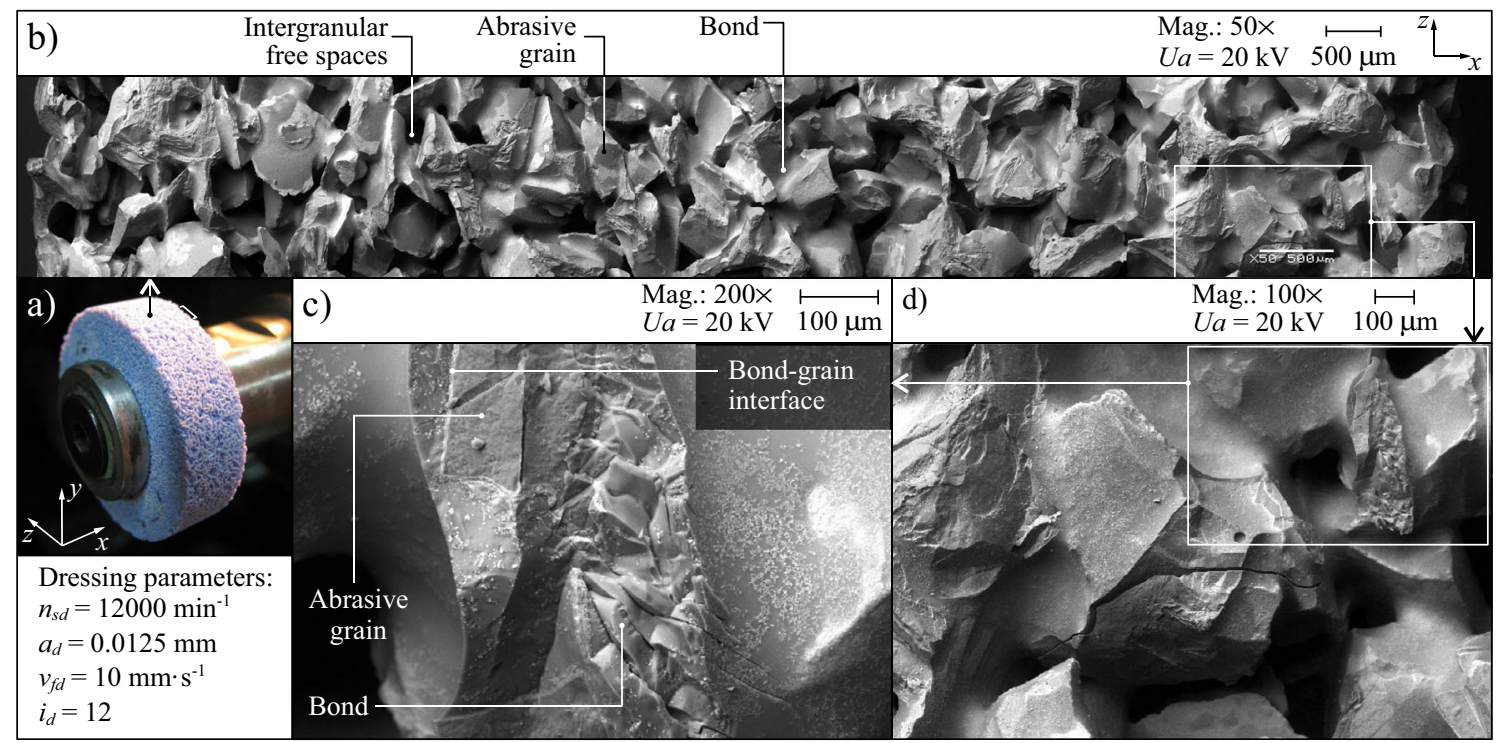

Fig. 3 SEM micrographs of the grinding wheel active surface after dressing: a macrography with overall view of the grinding wheel; $\mathbf{b}$ mag. $\times 50$; $\mathbf{c}$ mag. $\times 200$; d mag. $\times 100$ 
Fig. 4 Changes of values of selected workpiece surface roughness parameters and grinding power gain $\Delta P$ over material removal $V_{w}$ during internal cylindrical plunge grinding with oscillations: a arithmetic mean deviation of the workpiece profile $R a$; b maximum height of profile within sampling length $R z$; c mean width of roughness profile elements within sampling length $R S m ; \mathbf{d}$ root-mean-square slope of profile within sampling length $R d q$; e grinding power gain $\Delta P$
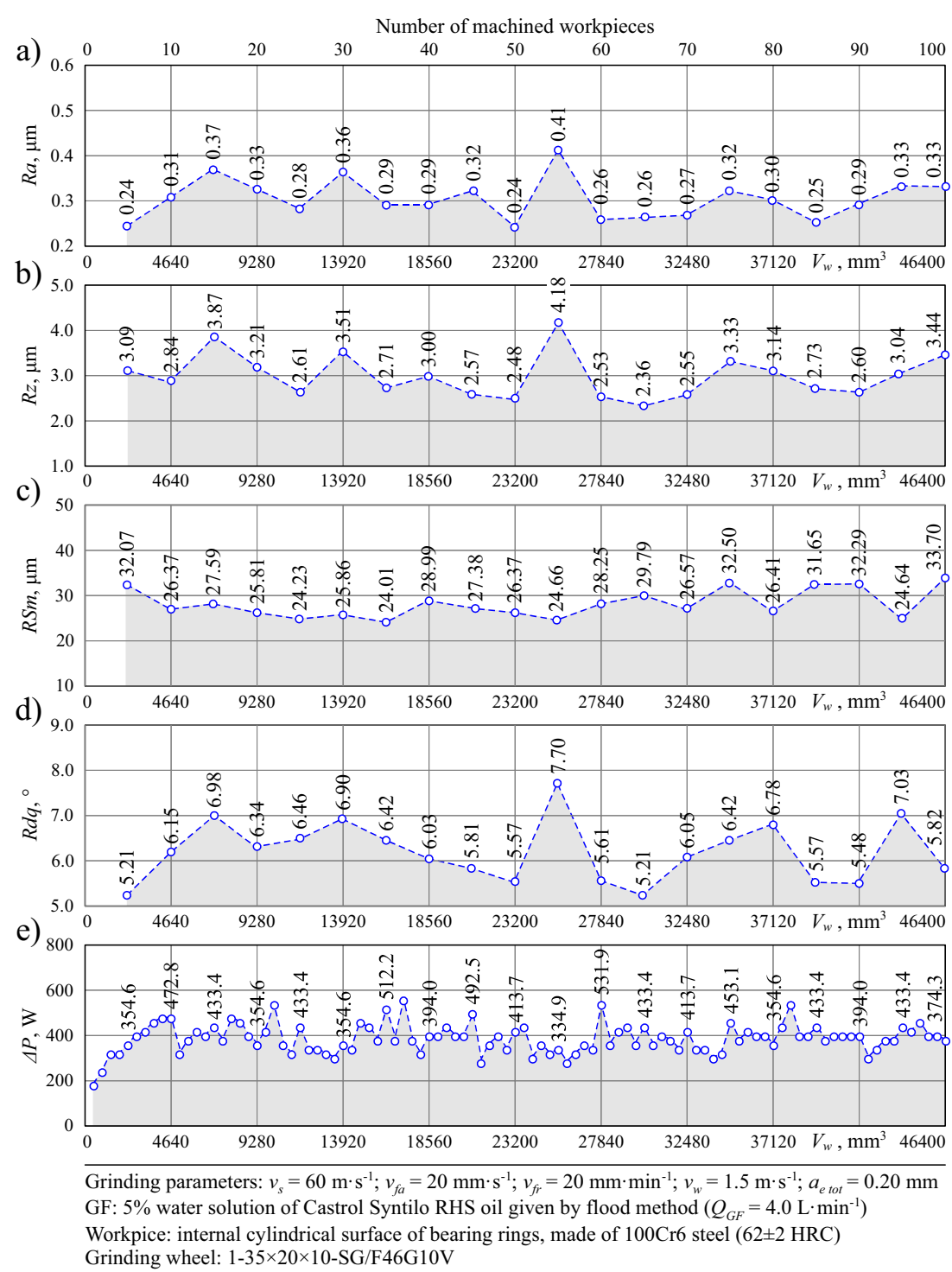

carried out by the use of tabletop contact roundness meter PIK-1A produced by Institutional-Industrial Center for Metrology and Measurement Systems of Warsaw University of Technology (Poland). The results of the plunge internal cylindrical grinding process in a form of SEM micrographs of the GWAS and chips under various magnifications was acquired by a scanning electron microscope, namely a JSM-5500LV produced by JEOL Ltd. (Japan). The general views of the abovementioned systems are presented in Fig. 2.

\subsection{Results and discussion}

Figure 3 shows microscopic SEM views of the GWAS after dressing. Analysis of these micrographs showed high degree of openness of the grinding wheel structure with numerous intergranular free spaces which facilitated the reaching of grinding fluid into the grinding zone, thereby removing the products of grinding process (chips, crushed particles of abrasive grains, and bond bridges). As the tested wheel was new, the GWAS did not registered any contamination, only standard components of grinding wheel such as sharpened vertices of microcrystalline sintered corundum abrasive grains, bridges of vitrified bond, and intergranular free spaces.

Figure 4 contains charts of the values changes of the selected workpiece surface roughness parameters (Fig. 4a-d) and grinding power gain $\Delta P$ (Fig. 4e) over material removal $V_{w}$ during internal cylindrical plunge grinding with oscillations conducted for 100 workpieces $\left(V_{w}=46,400 \mathrm{~mm}^{3}\right)$. Analysis of parameter $R a$ (Fig. 4a), $R z$ (Fig. 4b), $R S m$ (Fig. 4c), and $R d q$ (Fig. 4d) values indicates the stable operation of the wheel, which shaped surfaces of workpieces with a roughness in the range of $R a=0.24-0.41 \mu \mathrm{m}$. Moreover, the measured values of grinding power gain $\Delta P$ (Fig. $4 \mathrm{e}$ ) remained relatively stable throughout the period of the grinding wheel's operation. This demonstrates the effective reach of the grinding fluid (GF) 
Fig. 5 Changes of values of the maximum roundness deviation $\Delta$ (a) and root-mean-square deviation from mean circle $r m s$ (b) over material removal $V_{w}$ as well as circumference profiles of tested grinding wheels after dressing (c) and after internal cylindrical plunge grinding with oscillations $(\mathbf{d}-\mathbf{g})$

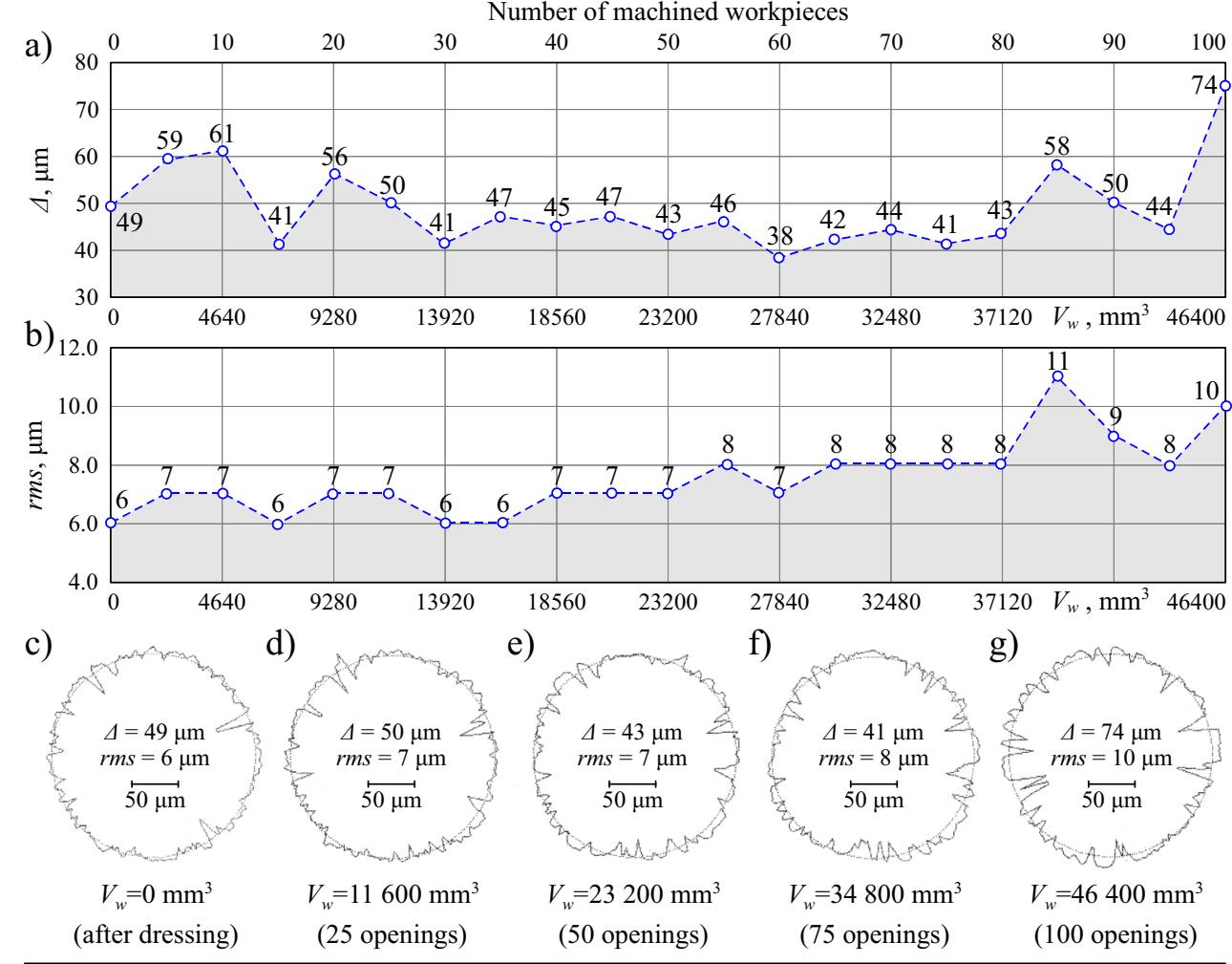

Grinding parameters: $v_{s}=60 \mathrm{~m} \cdot \mathrm{s}^{-1} ; v_{f a}=20 \mathrm{~mm} \cdot \mathrm{s}^{-1} ; v_{f r}=20 \mathrm{~mm} \cdot \mathrm{min}^{-1} ; v_{w}=1.5 \mathrm{~m} \cdot \mathrm{s}^{-1} ; a_{\text {e tot }}=0.20 \mathrm{~mm}$ GF: $5 \%$ water solution of Castrol Syntilo RHS oil given by flood method $\left(Q_{G F}=4.0 \mathrm{~L} \cdot \mathrm{min}^{-1}\right)$

Workpice: internal cylindrical surface of bearing rings, made of $100 \mathrm{Cr} 6$ steel $(62 \pm 2 \mathrm{HRC})$

Grinding wheel: $1-35 \times 20 \times 10-S G / F 46 G 10 \mathrm{~V}$ into the grinding zone, as well as the cyclical renewal of active vertices' cutting ability of the microcrystalline sintered corundum abrasive grains.

Analysis of parameters describing the recorded changes in roundness deviation of the grinding wheel during the tests (Fig. 5) confirmed uniform wear of the abrasive grains on the perimeter of the wheel. Of note, however, was a progressive increase in the value of root-mean-square deviation from mean circle rms (Fig. 5b), which indicates the slow loss of the circular axle outline of the grinding wheel, originally formed in the dressing cut. This phenomenon seems to intensify during the final period of operation of the wheel (opening nos. 80-100).

Figure 6 describes the average values (with standard deviation) of the selected workpiece surface roughness parameters (Fig. 6a-d), grinding power gain (Fig. 6e), and roundness deviation of the GWAS (Fig. 6f-g) after grinding. Additionally, the G-ratio (which is a dimensionless ratio of material removal $V_{w}$ to volumetric grinding wheel wear $V_{s}$ ) was also calculated for the described grinding test (Fig. 6f). The small value of scatter measure (standard deviation in this case) of designated parameters (Fig. 6a-g) demonstrated the stable operation of the tested wheel, while the value of the G-ratio at a level of about 100 should be regarded as satisfactory for an internal cylindrical grinding process conducted using small-dimensional $\mathrm{Al}_{2} \mathrm{O}_{3}$ grinding wheel.

Figures 7, 8, 9, 10, 11, and 12 show SEM micrographs of chips and GWAS recorded after the first stage of the study, in which one workpiece was ground (Figs. 7, 8, and 9) and, after the second stage, in which 100 workpieces were machined (Figs. 10, 11, and 12).

Figures 7, 8, and 9a-c present the morphology of chips caught during grinding process directly after the dressing cut of the grinding wheel. The flowing-type chips which they display are relatively large (several hundred $\mu \mathrm{m}$ in length) and are the result of material removal by the sharp cutting edges of abrasive grain active vertices from the workpiece surface made of 100Cr6 steel. Observations of the GWAS after grinding (Figs. 9d-f) reveal that, apart from large flowing-type chips, much smaller shearing-type, knife-type, slice-type, and spherical melted chips [12] are also formed, as a result of surface smoothing in the final phase of the grinding process. It seems, however, that the dominant type of chips, shaped in the initial period of the grinding wheel's life, are large flowing-type chips, as presented in Figs. 7, 8, and $9 \mathrm{a}-\mathrm{c}$. Analysis of the GWAS's condition after removal of $464 \mathrm{~mm}^{3}$ of workpiece material (Figs. 9d-f) reveals a lack of clogging, either at the vertices of active abrasive grains or in 

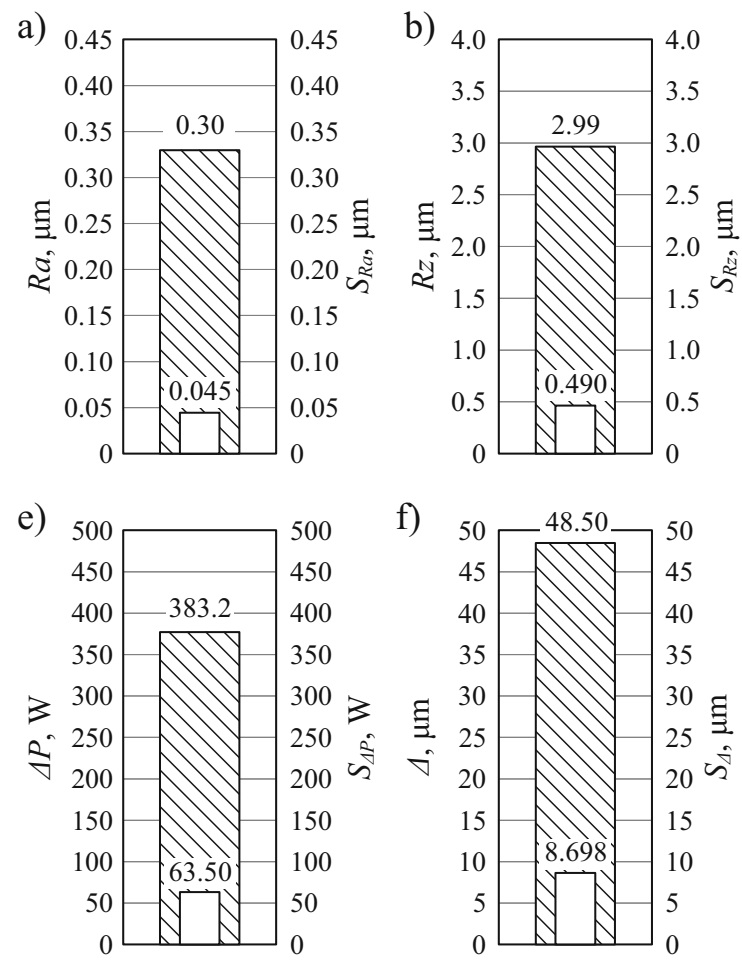

Fig. 6 Values of selected workpiece surface roughness parameters, grinding power, roundness deviation of GWAS designated as average of results for 100 ground openings $\left(V_{w}=46,400 \mathrm{~mm}^{3}\right)$ as well as G-ratio: a arithmetic mean deviation of workpiece profile $R a$; b maximum height of profile within sampling length $R z$; $\mathbf{c}$ mean width

the intergranular spaces. The grains have still sharp cutting edges with only slight visible marks of abrasive wear. Intergranular spaces are free of grinding products while steel saw cracks remain after the dressing cut on the GWAS (Fig. 9d).

Since internal cylindrical plunge grinding with oscillations is characterized by the simultaneous occurrence of plunge $\left(v_{f r}\right)$ and axial $\left(v_{f a}\right)$ movement, three characteristic zones are formed during the long term of operation on the GWAS. Near the edges of the GWAS, high removal of the workpiece material takes place, while in the central zone, finish grinding and sparking-out predominate. Thus, in order to fully describe the condition of the GWAS and chip morphology, SEM micrographs were recorded separately for each of these GWAS zones (left side, Fig. 10; middle area, Fig. 11; right side, Fig. 12).

Areas near the edge of the grinding wheel (Figs. 10 and 12) have a comparable condition to the GWAS. Active vertices of abrasive grains have clear signs of fatigue and thermo-fatigue wear. They also display signs of an ongoing process of renewal of their cutting ability through microchipping and exfoliation of a plastically deformed grain layer (Figs. 10d, f, g and 12b). Characteristic for these areas are also microcloggings on the active grain vertices (Figs. 10f, g and 12b). In near-edge areas of the GWAS, part of intergranular spaces were left free,
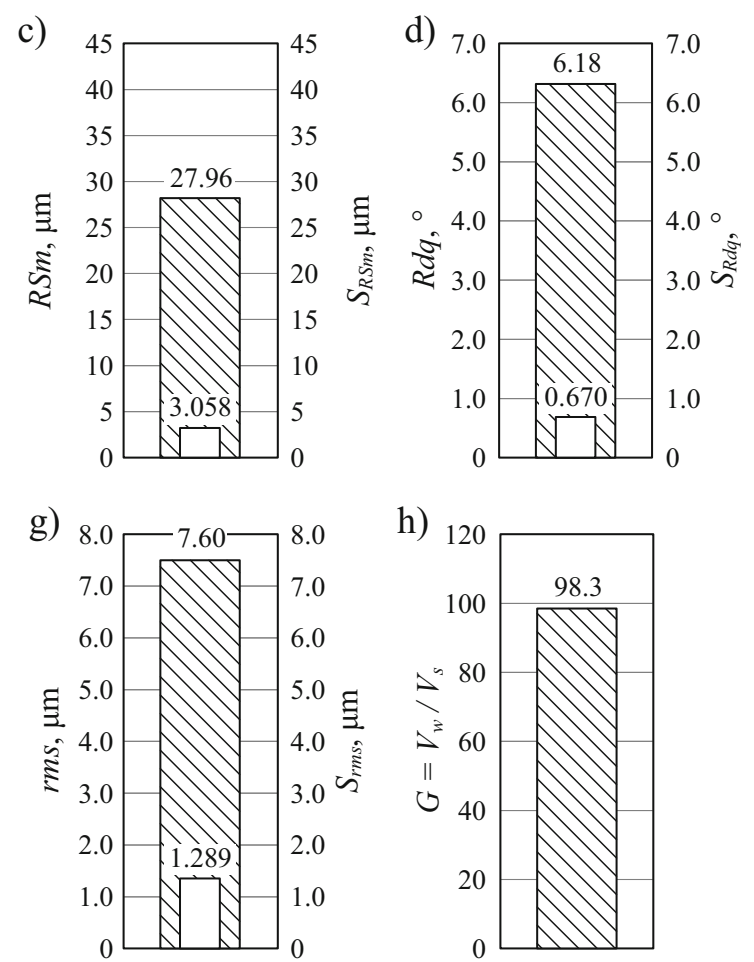

of roughness profile elements within sampling length $R S m$; d root-meansquare slope of the profile within sampling length $R d q$; $\mathbf{e}$ grinding power gain $\Delta \mathrm{P} ; \mathbf{f}$ maximum roundness deviation $\Delta ; \mathbf{g}$ root-mean-square deviation from mean circle $r m s$; h G-ratio ( $S$ standard deviation, $V_{s}$ volumetric grinding wheel wear)

which indicates the effective leaching of grinding products by the GF given by flood method (Figs. 10b and 12d). However, in the central zone of the grinding wheel (Fig. 11), the intergranular spaces are covered by a large amount of microchips generated during finish grinding. On the surface of this part of the grinding wheel, extensive cloggings near the active grain vertices can be observed (Fig. 11b-c). The surfaces of abrasive grains are smoothed through abrasive wear and plastic flow (Fig. 11b-e).

The above-described differences in the condition of individual zones of the GWAS also affect the size and type of chips observed in them. Only in the near-edge zones can flowing-type and shearing-type chips be observed, characteristic for the effective removal of workpiece material by sharp edges of abrasive grains (Figs. 10c, e and 11e-g). Shearingtype chips are usually long and straight while flowing-type chips are more slender and curly. However, the size of the chips is several times smaller (usually less than $100 \mu \mathrm{m}$ ) than the chips obtained in the course of grinding using a grinding wheel directly after the dressing cut (Figs. 7, 8, and 9a-c). On the whole, GWAS is dominated by knife-type and slice-type microchips accumulated during grinding of the subsequent openings (Figs. 10c, e, 11d, f, g, and 12c, f, g). The slicetype and knife-type microchips are related to the presence of microcloggings on the abrasive grain active vertices and are 

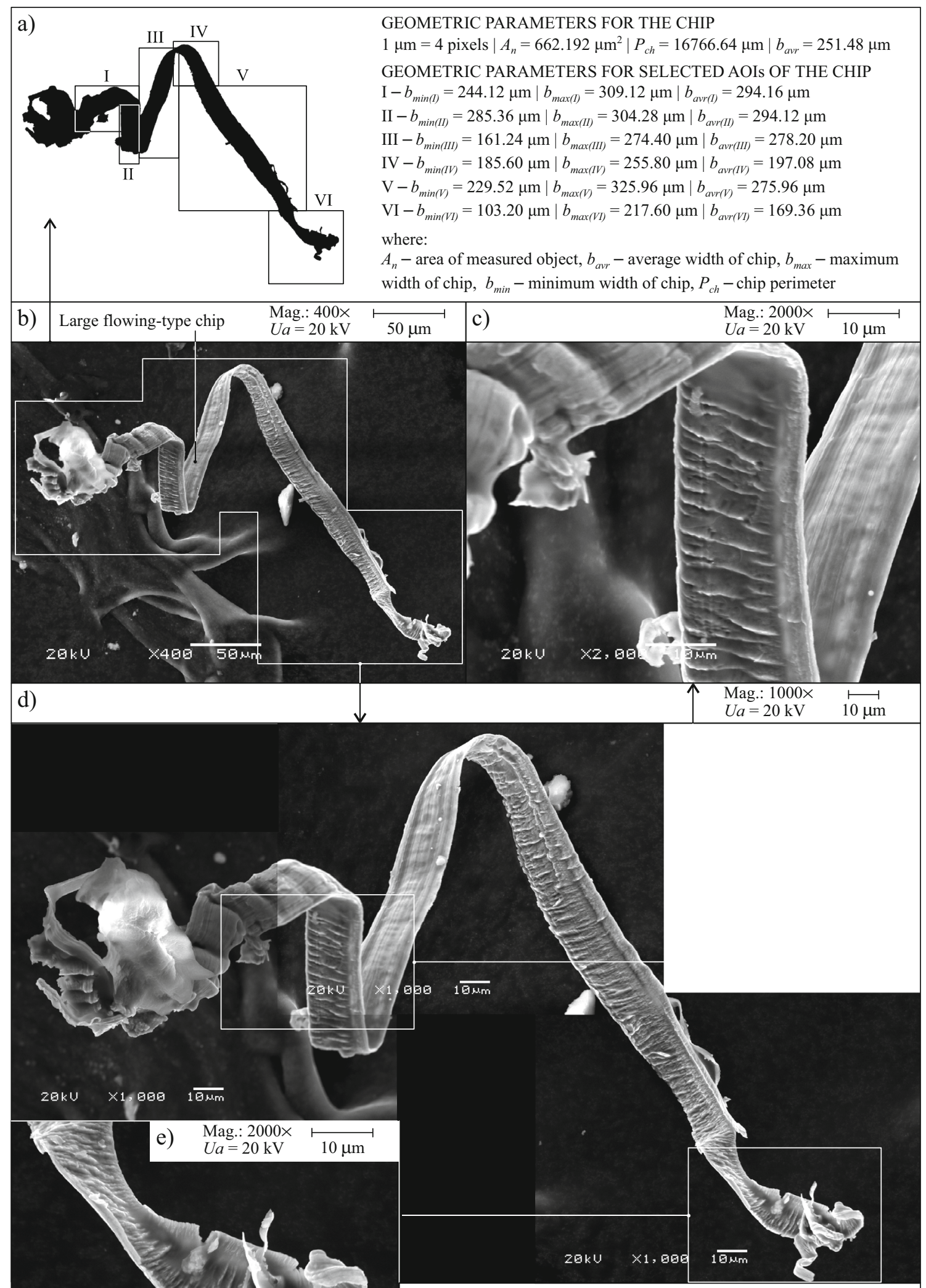

Grinding parameters: $v_{s}=60 \mathrm{~m} \cdot \mathrm{s}^{-1} ; v_{f a}=20 \mathrm{~mm} \cdot \mathrm{s}^{-1} ; v_{f r}=20 \mathrm{~mm} \cdot \mathrm{min}^{-1}$; $v_{w}=1.5 \mathrm{~m} \cdot \mathrm{s}^{-1} ; a_{\text {etot }}=0.20 \mathrm{~mm} ; V_{w}=464 \mathrm{~mm}^{3} ; Q_{G F}=4.0 \mathrm{~L} \cdot \mathrm{min}^{-1}$ GF: $5 \%$ water solution of Castrol Syntilo RHS oil given by flood method Workpice: internal cylindrical surface of bearing rings, made of $100 \mathrm{Cr} 6$ steel $(62 \pm 2 \mathrm{HRC})$ 
4 Fig. 7 Example no. 1 of SEM micrographs of workpiece chip caught during grinding conducted using grinding wheel after dressing (one opening ground $-V_{w}=464 \mathrm{~mm}^{3}$ ): a geometric analysis; b mag. $\times 400$; c mag. $\times 2000$; d mag. $\times 1000$; e mag. $\times 2000$

the loading area that fall from the grinding wheel. Regardless of the area of the grinding wheel, a few spherical melted chips of various sizes can be observed on its whole surface (Figs. 10c, e, 11g, and 12g). Melted chips always occur when a large amount of grinding heat is generated and conducted into the chips. The heat impact causes that spherical chips form as a result of grinding debris undergoing surface oxidation in the atmosphere [7,8]. The presence of such chips indicates that during the grinding process, there are microareas

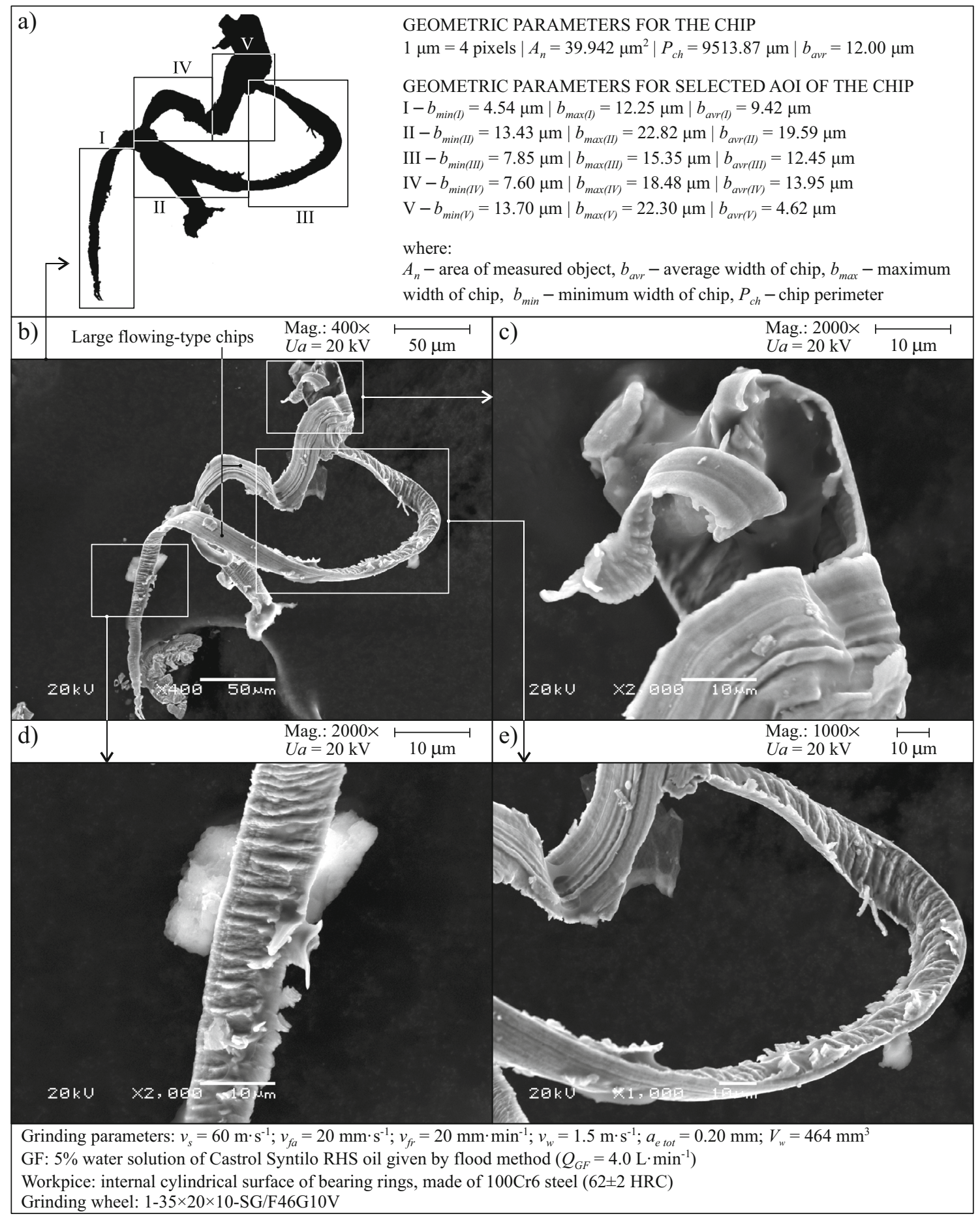

Fig. 8 Example no. 2 of SEM micrographs of workpiece chip caught during grinding conducted using grinding wheel after dressing (one opening ground $\left.-V_{w}=464 \mathrm{~mm}^{3}\right)$ : a geometric analysis; $\mathbf{b}$ mag. $\times 400$; $\mathbf{c}, \mathbf{d}$ mag. $\left.\times 2000 ; \mathbf{e}\right)$ mag. $\times 1000$ 
Fig. 9 Example no. 3 of SEM micrographs of workpiece chip caught during grinding (a-d), as well as micrographs of chips observed on GWAS (e-g) after one opening ground $\left(V_{w}=464 \mathrm{~mm}^{3}\right)$ : a mag. $\times 250$; b mag. $\times 500$; c mag. $\times 1000$; d geometric analysis; e mag. $\times 50$; f mag. $\times 150$; g mag. 500

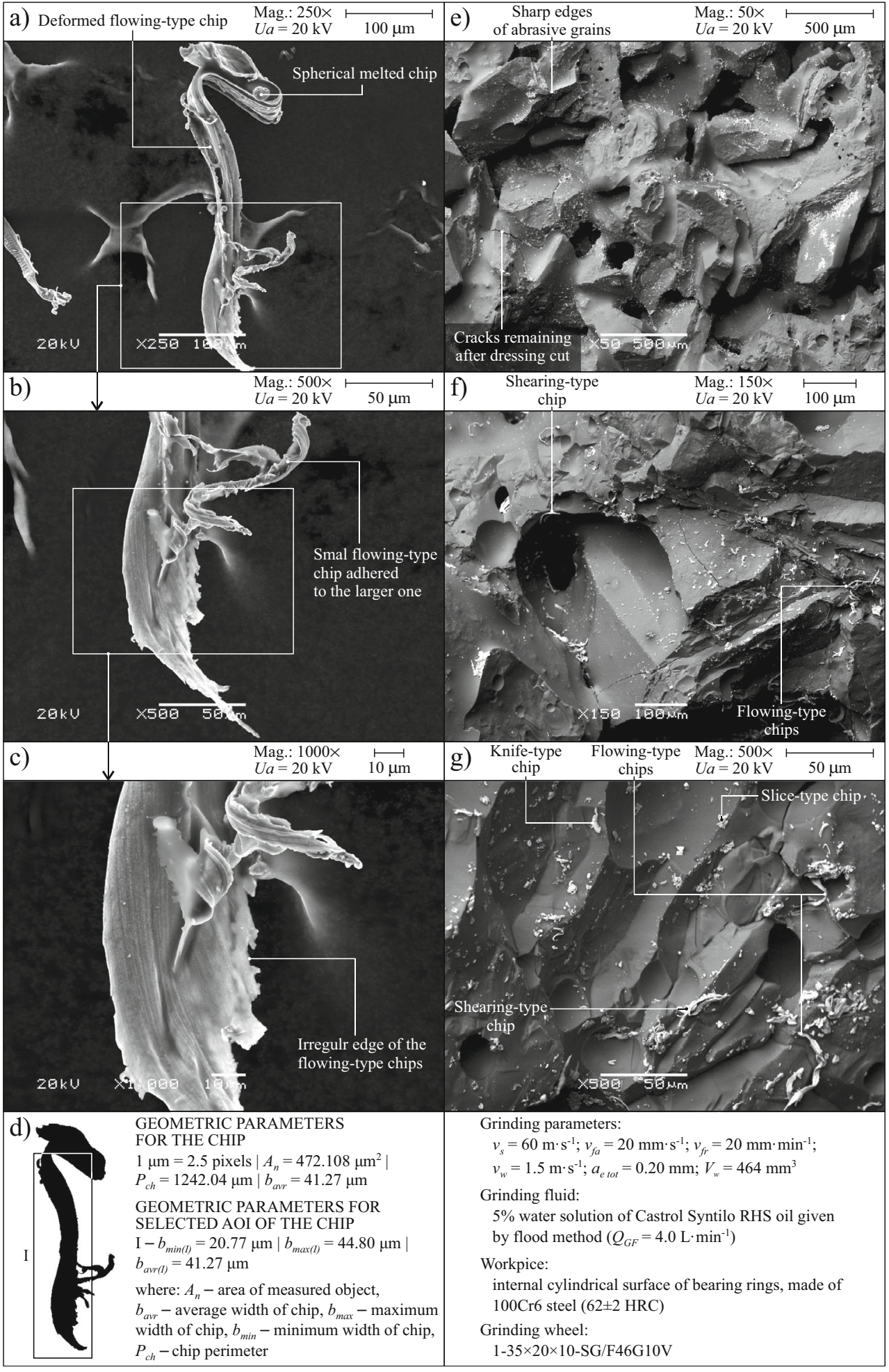

of the GWAS where a sufficient amount of grinding fluid does not reach.

In analyzing the connection between changes in the state of the GWAS and the size and type of the chips generated in the grinding process described, it should be emphasized that the observed changes of the wheel's condition did not significantly affect the values of the process output factors (workpiece surface roughness, grinding power, and roundness deviation of the grinding wheel). This demonstrates the ability to renew the cutting ability of a grinding wheel made of solgel alumina abrasive grains and a glass-crystalline bond. However, the deteriorating condition of the wheel may 


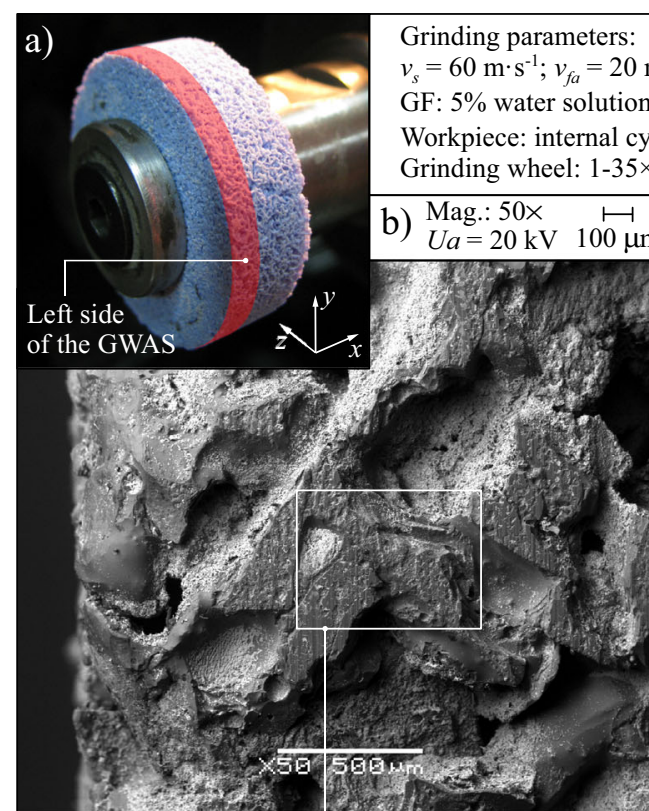

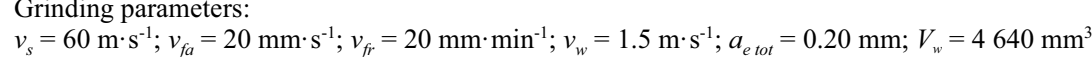
GF: $5 \%$ water solution of Castrol Syntilo RHS oil given by flood method $\left(Q_{G F}=4.0 \mathrm{~L} \cdot \mathrm{min}^{-1}\right)$ Workpiece: internal cylindrical surface of bearing rings, made of $100 \mathrm{Cr} 6$ steel $(62 \pm 2 \mathrm{HRC})$ Grinding wheel: 1-35×20×10-SG/F46G10V
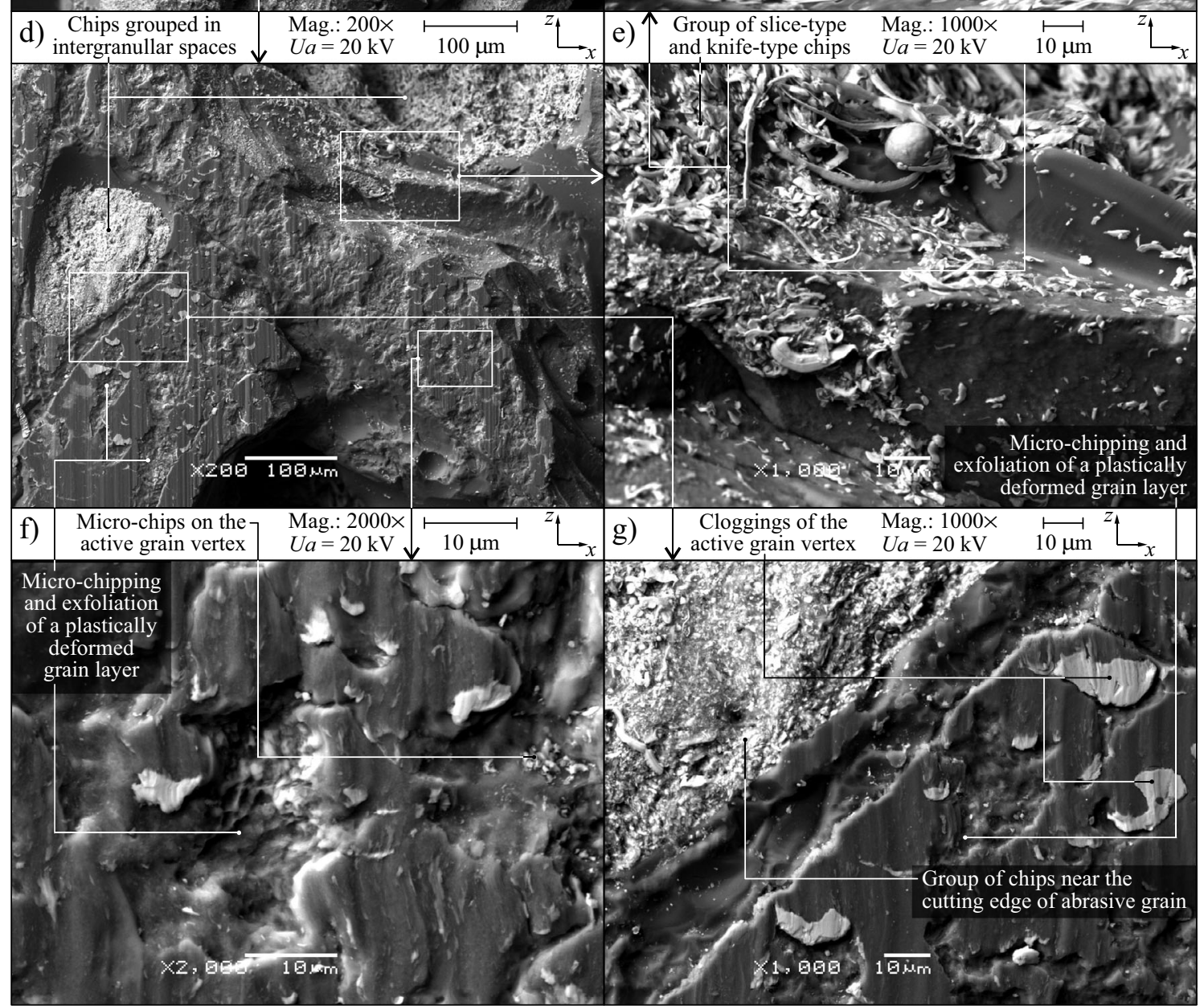

Fig. 10 SEM micrographs of chips observed on left side of the GWAS after 100 openings ground $\left(V_{w}=46400 \mathrm{~mm}^{3}\right)$ : a macrography of the grinding wheel with selected area of observation; b mag. $\times 50$; c mag. $\times 2000$; d mag. $\times 200$; e mag. $\times 1000$; f mag. $\times 2000$; g mag. $\times 1000$

adversely affect the thermal conditions in the zone of contact with the workpiece surface and eventually lead to grinding defects (burning, metallurgical phase transformations, tempering of the surface layer with possible rehardening, unfavorable 


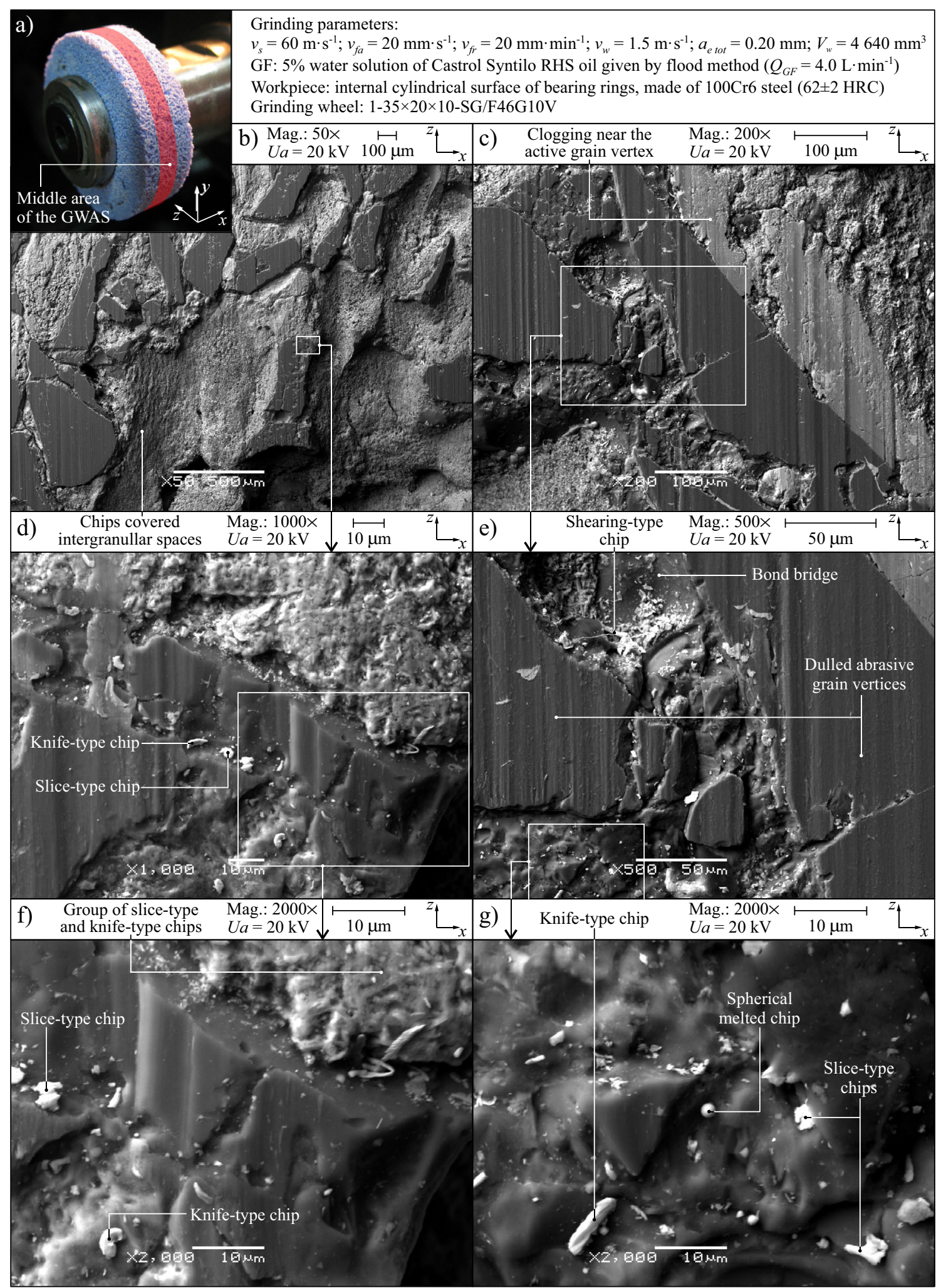

Fig. 11 SEM micrographs of chips observed in middle area of the GWAS after 100 openings ground $\left(V_{w}=46400 \mathrm{~mm}^{3}\right)$ : a macrography of grinding wheel with selected area of observation; b mag. $\times 50$; $\mathbf{c}$ mag. $\times 200$; d mag. $\times 1000$; e mag. $\times 500$; f mag. $\times 2000$; g mag. $\times 2000$

residual tensile stresses, cracks, and reduced fatigue strength). Analysis of the chips generated in the grinding process is one of the sources of information regarding process's temperature.
The appearance of spherical chips, as well as an increase in their share in relation to other types of chips, result in the limited reach of GF to the contact zone between the active 


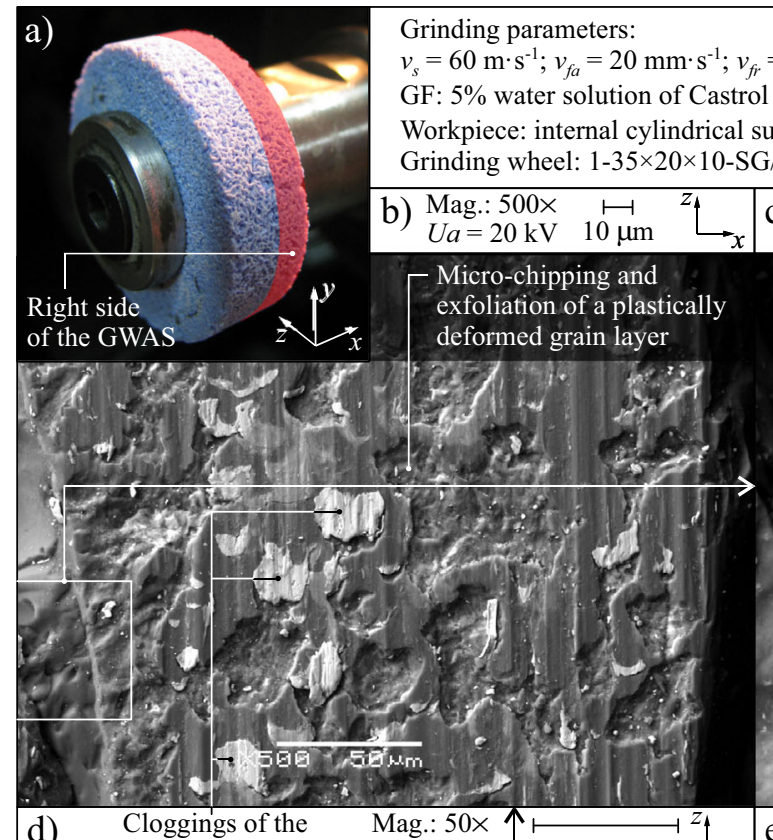

Grinding parameters:
$v_{s}=60 \mathrm{~m} \cdot \mathrm{s}^{-1} ; v_{f a}=20 \mathrm{~mm} \cdot \mathrm{s}^{-1} ; v_{f r}=20 \mathrm{~mm} \cdot \mathrm{min}^{-1} ; v_{w}=1.5 \mathrm{~m} \cdot \mathrm{s}^{-1} ; a_{\text {etot }}=0.20 \mathrm{~mm} ; V_{w}=4640 \mathrm{~mm}^{3}$ GF: $5 \%$ water solution of Castrol Syntilo RHS oil given by flood method $\left(Q_{G F}=4.0 \mathrm{~L} \cdot \mathrm{min}^{-1}\right)$ Workpece internal cylindrical surface of bearing rings, made of $100 \mathrm{Cr} 6$ steel $(62 \pm 2 \mathrm{HRC})$ Grinding wheel: $1-35 \times 20 \times 10-\mathrm{SG} / \mathrm{F} 46 \mathrm{G} 10 \mathrm{~V}$
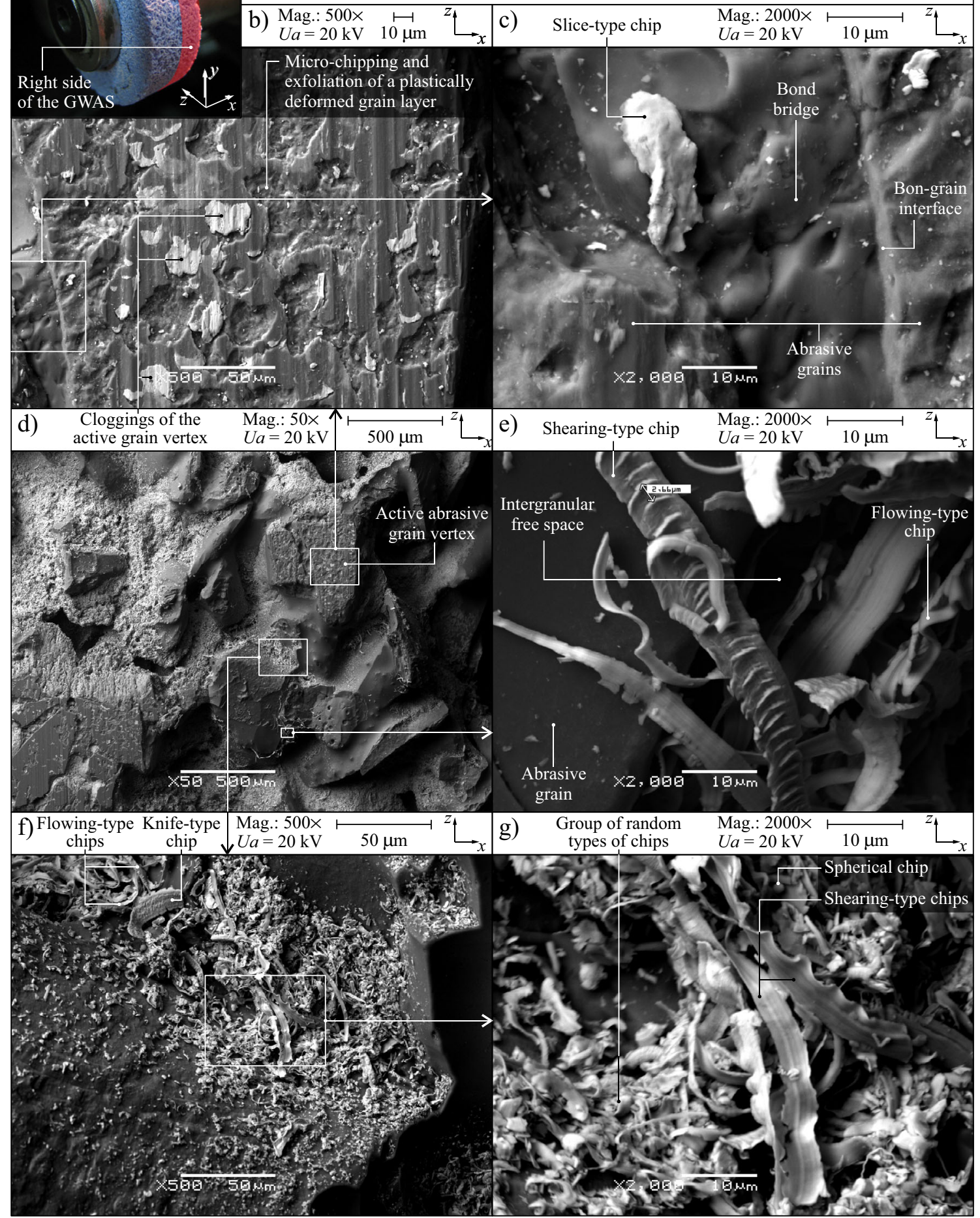

Fig. 12 SEM micrographs of chips observed on right side of the GWAS after 100 openings ground $\left(V_{w}=46400 \mathrm{~mm}^{3}\right)$ : a macrography of grinding wheel with selected area of observation; b mag. $\times 500$; $\mathbf{c}$ mag. $\times 2000$; $\mathbf{d}$ mag. $\times 50$; $\mathbf{e}$ mag. $\times 2000$; f mag. $\times 500$; $\mathbf{g}$ mag. $\times 2000$

cutting vertices and the workpiece surface. Although precise observations of such chips are neither feasible nor costeffective in industrial conditions, they are an important element of the process assessment in the laboratory during research and development, as evidenced by publications in this field cited earlier in this work. 


\section{Conclusions}

The wide range of analysis of chip morphology presented in this text, as well as of the grinding wheel active surface condition (before and after grinding), allows one to formulate credible conclusions regarding the effect of wear phenomena on grinding wheels with sol-gel alumina abrasive grains on chip formation during internal cylindrical plunge grinding of $100 \mathrm{Cr} 6$ steel. This analysis covered both the size and types of chips on the basis of a comprehensive recorded set of SEM micrographs. The most important conclusions that can be drawn from the research carried out include the following:

- The dominant type of chips, shaped in the initial period of the grinding wheel's life, are large (several hundred $\mu \mathrm{m}$ in length) flowing-type chips resulting from material removal by the sharp cutting edges of abrasive grain active vertices.

- At the end of the grinding wheel's life, when the active vertices of abrasive grains have clear signs of large fatigue and thermo-fatigue wear, three characteristic zones are formed on the GWAS: two near-edge zones where high removal of the workpiece material takes place and central zone where finish grinding and sparking-out predominate.

- Differences in the condition of individual zones of the GWAS affect the size and type of chips observed on them: only in the near-edge zones can flowing-type and shearing-type chips (usually less than $100 \mu \mathrm{m}$ in length) be observed, while knife-type and slice-type microchips were observed on the whole GWAS.

- On the whole surface of the grinding wheel observed a few spherical melted chips of various sizes were also observed, indicating that during the grinding process, a large amount of grinding heat is generated and conducted into the chips.

The conducted experimental research and analysis of the results allowed one to broaden one's knowledge of elementary phenomena occurring in the contact zone of the sol-gel alumina abrasive grains with the workpiece surface during a longduration operation of the wheel, with particular emphasis on the form of chips generated. Indeed, knowledge concerning the relationship between the state of various functional zones (resulting from the plunge grinding process) of the grinding wheel made from sol-gel alumina grains, as well as the size and form of the chips, can form a basis for designing innovative grinding wheels, taking into account the factors described. The purpose of such modifications can be either the extension of the wheel's life (e.g., by increasing the pore volume which supports the transport of chips out of the grinding zone), or increasing the use of the cutting ability of sol-gel abrasive grains which are distinguished by a specific course of wear process as described earlier. As a result, it would be possible to reduce the costs associated with the purchase and operation of such tools.

Acknowledgments The authors would like to thank the employees of the Koszalin University of Technology for their help and support in selected steps of the experimental investigations: Mrs. Daniela Herman, $\mathrm{DSc}, \mathrm{PhD}$, from the Division of Fundamentals of Materials Science and Technical Ceramics of the Faculty of Technology and Education, for preparing the grinding wheels for tests; Mr. Andrzej Nowicki from Laboratory Team I for his help during experimental investigations of the grinding process; Mr. Krzysztof Maciejewski from the Laboratory of Metrology and Measurement Systems for the stylus measurements of surface microtopographies of the workpieces; as well as Mr. Ryszard Gritzman from the Central Laboratory of the Faculty of Technology and Education for acquisition of the SEM micrographs.

\section{Compliance with ethical standards}

Funding This study did not receive any grant funding.

Conflict of interest The authors declare that they have no conflict of interest.

Open Access This article is distributed under the terms of the Creative Commons Attribution 4.0 International License (http:// creativecommons.org/licenses/by/4.0/), which permits unrestricted use, distribution, and reproduction in any medium, provided you give appropriate credit to the original author(s) and the source, provide a link to the Creative Commons license, and indicate if changes were made.

\section{References}

1. Neslusan M, Cep R (2008) Aspects of chip formation during turning of hardened steel 100Cr6. ATMiA 28(4):13-23

2. Dabade UA, Joshi SS (2009) Analysis of chip formation mechanism in machining of $\mathrm{Al} / \mathrm{SiCp}$ metal matrix composites. J Mater Process Tech 209:4704-4710

3. Ebrahimi A, Moshkar MM (2009) Evaluation of machinability in turning of microalloyed and quenched-tempered steels: Tool wear, statistical analysis, chip morphology. J Mater Process Tech 209: 910-921

4. ZhangS GYB (2009) An experimental and analytical analysis on chip morphology, phase transformation, oxidation, and their relationships in finish hard milling. Int J Mach Tool Manu 49:805-813

5. Li R, Riester L, Watkins TR, Blau PJ, Shih AJ (2008) Metallurgical analysis and nanoindentation characterization of Ti-6Al-4V workpiece and chips in high-throughput drilling. Mat Sci Eng A-Struct

6. Wong YC, Doyle ED (1999) Implications of high strain deformation in grinding. Wear 233-235:395-401

7. Malkin S (1979) Negative rake cutting to simulate chip formation in grinding. CIRP Ann-Manuf Techn 28:09-212

8. Doyle ED, Dean SK (1980) An insight into grinding from materials viewpoint. CIRP Ann-Manuf Techn 29:571-575

9. Letner H (1995) Modern perspective of grinding process. Grinding and Finishing 1:36

10. Tso PL, Wu SH (1999) Analysis of grinding quantities through chip sizes. J Mater Process Tech 95:1-7 
11. Vedhavalli L, Lavanya TD, Annamalai VE (2007) The presence of carbon content in chips as an indicator of grinding temperature. Mater Manuf Process 22(7-8):830-832

12. Tso PL (1995) An investigation of chip types in grinding. J Mater Process Tech 53:521-532

13. Ronald BA, Vijayaraghavan L, Krishnamurthy R (2010) Chip morphology: an indicator of response of composite material to grinding. Int J Mater Prod Tec 37(1-2):71-82

14. Peng Y, Liang Z, Wu Y, Guo Y, Wang C (2012) Characteristics of chip generation by vertical elliptic ultrasonic vibration-assisted grinding of brittle materials. Int J Adv Manuf Tech 62:563-568

15. Nadolny K, Sienicki W, Wojtewicz M (2015) The effect upon the grinding wheel active surface condition when impregnating with non-metallic elements during internal cylindrical grinding of titanium. Arch Civ Mech Eng 15(1):71-86

16. Feng BF, Cai GQ, Sun XL (2006) Groove, chip and force formation in single grain high-speed grinding. In: Cai G, Xu XP, Kang R (eds) Advances in grinding and abrasive technology XIII. Trans Tech Publications, Stafa-Zurich, pp 196-200

17. Zhao HH, Cai GQ, Gao XJ, Xu C (2006) Study on chip formation mechanism due to chock of ultra-high speed grinding Q235A. In: Jia Z, Wang XY, Wang J (eds) Current development in abrasive technology, proceedings. Frontiers Design Manufacturing, Riverwood, pp 45-50

18. Zhao JY, Fu YC, Xu JH, Tian L, Yang L (2013) Forces and chip morphology of Nickel-based superalloy Inconel 718 during high speed grinding with single grain. In: Xu X, Huang C, Zuo D, Chen M (eds) Advances in grinding and abrasive technology XII. Trans Tech Publications, Stafa-Zurich, pp 209-214

19. Brinksmeler E, Glwerzew A (2003) Chip formation mechanism in grinding at low speeds. CIRP Ann-Manuf Techn 52:253-258

20. Gopal AV, Rao PV (2004) A new chip-thickness for performance assessment of silicon carbide grinding. Int J Adv Manuf Tech 24(11-12):816-820
21. Jin T, Stephenson DJ (2006) Analysis of grinding chip temperature and energy partitioning in high-efficiency deep grinding. P I Mech Eng B-J Eng 220:615-625

22. Agarwal S, Rao PV (2013) Predictive modeling of force and power based on a new analytical undeformed chip thickness model in ceramic grinding. Int J Mach Tool Manu 65:68-78

23. Zhu D, Yan S, Li B (2014) Single-grit modeling and simulation of crack initiation and propagation in $\mathrm{SiC}$ grinding using maximum undeformed chip thickness. Comp Mater Sci 92:13-21

24. Hecker RL, Liang SY, Wu XJ, Xia P, Wei Jin DG (2007) Grinding force and power modeling based on chip thickness analysis. Int J Adv Manuf Tech 33(5-6):449-459

25. Setti D, Sinha MK, Ghosh S, Rao PV (2015) Performance evaluation of Ti-6Al- $4 \mathrm{~V}$ grinding using chip formation and coefficient of friction under the influence of nanofluids. Int J Mach Tool Manu 88:237-248

26. Klocke F (2009) Manufacturing processes 2: grinding, honing, lapping. Springler-Verlag, Berlin

27. Rowe WB (2009) Principles of modern grinding technology. William Andrew, Burlington

28. Klocke F, Engelhorn R, Mayer J, Weirich T (2002) Micro-analysis of the contact zone of tribologically loaded second-phase reinforced sol-gel-abrasives. CIRP Ann-Manuf Techn 51:245-250

29. Mayer J, Engelhorn R, Bot R, Weirich T, Herwartz C, Klocke F (2006) Wear characteristics of second-phase-reinforced sol-gel corundum abrasives. Acta Mater 54:3605-3615

30. Nadolny K (2014) State of the art in production, properties and applications of the microcrystalline sintered corundum abrasive grains. Int J Adv Manuf Tech 74(9):1445-1457

31. Nadolny K (2015) Wear phenomena of grinding wheels with solgel alumina abrasive grains and glass-ceramic vitrified bond during internal cylindrical traverse grinding of $100 \mathrm{Cr} 6$ steel. Int J Adv Manuf Tech 77(1-4):83-98 